\title{
Front Matter: Volume 11436
}

, "Front Matter: Volume 11436," Proc. SPIE 11436, 2019 International Conference on Optical Instruments and Technology: Optical Sensors and Applications, 1143601 (12 March 2020); doi: 10.1117/12.2566174

SPIE Event: 2019 International Conference on Optical Instruments and Technology, 2019, Beijing, China 


\title{
PROCEEDINGS OF SPIE
}

\section{International Conference on Optical Instruments and Technology}

\section{Optical Sensor and Applications}

\author{
Xuping Zhang \\ Hai Xiao \\ Editors
}

26-28 October 2019

Beijing, China

Sponsored by

$\mathrm{CIS}$ - China Instrument and Control Society (China)

Cosponsored and Published by

SPIE

\section{Volume 11436}


The papers in this volume were part of the technical conference cited on the cover and title page. Papers were selected and subject to review by the editors and conference program committee. Some conference presentations may not be available for publication. Additional papers and presentation recordings may be available online in the SPIE Digital Library at SPIEDigitalLibrary.org.

The papers reflect the work and thoughts of the authors and are published herein as submitted. The publisher is not responsible for the validity of the information or for any outcomes resulting from reliance thereon.

Please use the following format to cite material from these proceedings:

Author(s), "Title of Paper," in 2019 International Conference on Optical Instruments and Technology: Optical Sensor and Applications, edited by Xuping Zhang, Hai Xiao, Proceedings of SPIE Vol. 11436 (SPIE, Bellingham, WA, 2020) Seven-digit Article CID Number.

ISSN: 0277-786X

ISSN: 1996-756X (electronic)

ISBN: 9781510636507

ISBN: 9781510636514 (electronic)

Published by

SPIE

P.O. Box 10, Bellingham, Washington 98227-0010 USA

Telephone +1 3606763290 (Pacific Time) · Fax +1 3606471445

SPIE.org

Copyright (c) 2020, Society of Photo-Optical Instrumentation Engineers.

Copying of material in this book for internal or personal use, or for the internal or personal use of specific clients, beyond the fair use provisions granted by the U.S. Copyright Law is authorized by SPIE subject to payment of copying fees. The Transactional Reporting Service base fee for this volume is $\$ 21.00$ per article (or portion thereof), which should be paid directly to the Copyright Clearance Center (CCC), 222 Rosewood Drive, Danvers, MA 01923. Payment may also be made electronically through CCC Online at copyright.com. Other copying for republication, resale, advertising or promotion, or any form of systematic or multiple reproduction of any material in this book is prohibited except with permission in writing from the publisher. The CCC fee code is $0277-$ $786 \mathrm{X} / 20 / \$ 21.00$.

Printed in the United States of America by Curran Associates, Inc., under license from SPIE.

Publication of record for individual papers is online in the SPIE Digital Library.

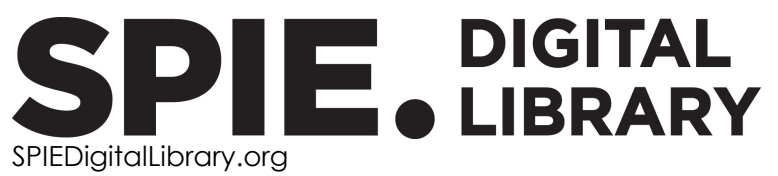

Paper Numbering: Proceedings of SPIE follow an e-First publication model. A unique citation identifier (CID) number is assigned to each article at the time of publication. Utilization of CIDs allows articles to be fully citable as soon as they are published online, and connects the same identifier to all online and print versions of the publication. SPIE uses a seven-digit CID article numbering system structured as follows:

- The first five digits correspond to the SPIE volume number.

- The last two digits indicate publication order within the volume using a Base 36 numbering system employing both numerals and letters. These two-number sets start with $00,01,02,03,04$, 05, 06, 07, 08, 09, OA, OB ... 0Z, followed by 10-1Z, 20-2Z, etc. The CID Number appears on each page of the manuscript. 


\title{
Contents
}

\author{
xii $\quad$ Authors \\ ix Symposium Committees \\ xi Conference Committee \\ xiii Introduction \\ xv Conference Organizers
}

OPTICAL SENSOR AND APPLICATIONS

1143602 Variational mode decomposition-based endpoint detection for distributed fiber interferometric vibration sensing systems (Invited Paper) [11436-2]

1143603 Performance enhancement for phase-sensitive OTDR based on multi-spatial resolution analysis (Invited Paper) [1 1 1436-3]

1143604 A multiple events recognition scheme based on improved feature vectors for fiber optic perimeter security system [1 1436-4]

$1143605 \quad$ Influence of wafer materials on the response speed of extrinsic optical fiber Fabry-Perot high temperature sensors (Invited Paper) [11436-6]

1143606 Temperature accuracy enhanced dual-end distributed temperature sensor employing Rayleigh compensation algorithm [1 1436-9]

$1143607 \quad$ An EMD-based filtering algorithm for the long period fiber grating sensing [11436-11]

1143608 Analysis on the interpolation of the weighted mean temperature and evaluation of GPT2w model in coastal areas of China [1 1436-13]

1143609 Application of spectral droplet analysis method in flammable liquids identification [11436-18]

$114360 \mathrm{~A} \quad$ Analysis the multiple-order coupling points in distributed polarization coupling measurement used graphical methods [11436-21]

$11436 \mathrm{OB} \quad$ Interferometric fiber optic surface plasmon resonance sensor for temperature and strain measurement [1 1436-25]

11436 OC Ultra-high temperature fiber growth technology based on $\mathrm{CO}_{2}$ laser-heated technology [1 1436-27] 
11436 OD Distributed optical fiber acoustic sensing method based on dual-chirped pulses and crosscorrelation analysis [1 1436-28]

$11436 \mathrm{OE} \quad$ Fabrication and sensing properties of fiber Mach-Zehnder sensor based on $\mathrm{CO}_{2}$ laser fusion [11436-30]

11436 OF Reflectivity-tunable Bragg grating reflectors based on polarization-maintaining few-mode fibers [11436-31]

11436 OG A weak double-peak fiber Bragg grating temperature sensor [11436-33]

$11436 \mathrm{OH}$ The effect of metal layer microstructure on optical fiber SPR sensor: a simulation study [11436-36]

11436 ol PDMS-coated fiber optic interferometer based on no-core fiber for multi-parameter measurements [11436-42]

$114360 \mathrm{~J} \quad$ Signal-pump power matching in the forward pumped fiber Raman amplifier of the remote interferometric optical fiber sensing system with phase modulation [1 1436-43]

11436 OK Simultaneous generation of multi-frequency microwave signals based on four-wave mixing in semiconductor laser with external cavity (Invited Paper) [11436-48]

$11436 \mathrm{OL} \quad$ Research on crack propagation identification of aluminum alloy based on micro-cavity array fiber [1 1436-49]

11436 OM Multispectral photoacoustic Doppler velocimetry with intensity modulated high repetition supercontinnum laser pulses [11436-52]

11436 ON Novel distributed fiber Raman sensor and its application (Invited Paper) [11436-53]

$1143600 \quad$ High temperature calibration of Raman distributed sensor based on dynamic multi-segment fiber temperature [11436-54]

$11436 \mathrm{OP} \quad$ Hybrid structured fiber-optic Fabry-Perot interferometer for simultaneous strain and temperature measurement base on phase demodulation [1 1436-55]

11436 OQ Distributed salinity sensor based on Brillouin dynamic grating (Invited Paper) [11436-60]

11436 OR Pedestrian detection and recognition using lidar for autonomous driving [1 1436-64]

11436 OS Optical fiber temperature and strain sensing system based on high accuracy time delay measurement [11436-65]

11436 OT Analysis method for the operation health of all-fiber optical current transformer [11436-66]

11436 OU Automatic segment assembly method of shield tunneling machine based on multiple optoelectronic sensors [11436-68]

11436 OV A transition edge sensor signal simulator to evaluate the performance of superconducting quantum interference device amplifier [11436-73] 
11436 OW Multi-point sensor based on SMS fiber structure [11436-74]

11436 OX Modeling method and discriminant criterion for single-particle image [1 1436-75]

11436 OY Pattern recognition of fiber disturbance based on support vector machine in polarization optical time domain reflectometry [1 1436-79]

$11436 \mathrm{OZ} \quad$ Birefringence and polarization properties of a spun fiber around conductor with electrical currents [11436-80]

1143610 Differential evolution algorithms for grating parameters and spatial stress decoupling of phaseshifted fiber Bragg grating [1 1436-81]

1143611 Application of plasma absorption method in transient radiation-induced loss analysis of optical fibers [1 1436-82]

1143612 Refractive index sensitivity of zinc oxide-coated long period fiber grating inscribed in a twomode fiber [11436-201] 
Proc. of SPIE Vol. 11436 1143601-6

\section{Downloaded From: https://www.spiedigitallibrary.org/conference-proceedings-of-spie on 26 Apr 2023 Terms of Use: https://www.spiedigitallibrary.org/terms-of-use}




\section{Authors}

Numbers in the index correspond to the last two digits of the seven-digit citation identifier (CID) article numbering system used in Proceedings of SPIE. The first five digits reflect the volume number. Base 36 numbering is employed for the last two digits and indicates the order of articles within the volume. Numbers start with 00, 01, 02, 03, 04, 05, 06, 07, 08, 09, OA, OB...0Z, followed by 10-1Z, 20-2Z, etc.

Baldovino-Pantaleón, Oscar, OW

Cai, Huaiyu, OF

Cao, Changqing, 00

Cao, Lu, 03

Chang, Pengxiang, $07, \mathrm{OH}$

Chen, Haixiu, 09

Chen, Wenjie, OD

Chen, Xiangfei, OG

Chen, Yusheng, 03

Chen, Yuzhi, OB

Dai, Ji, OG

Dai, Pan, OG

Deng, Jieqing, OT

Ding, Zhenyang, OD, OZ

Domínguez-Cruz, René F., OW

Dong, Jie, OE

Dong, Kaixian, OU

Dong, Yongkang, $0 Q$

Dou, Rongrong, $\mathrm{OY}$

Du, Rui, 06

Du, Xiangyu, 12

Fan, Xiaohui, OR

Fang, Hui, OM

Farooq, Tayyab, OM

Feng, Zhejun, 00

Fu, Chaoshuai, 06

Fu, Xuelei, OL

Fu, Yangting, OV

Fuentes-Rubio, Yadira A., OW

Gan, Haiyong, OV

Ghen, Youfu, OB, OI

Gong, Yuanxia, 11

Gu, Gaofei, OD

Gu, Jing, OY

Gui, Xin, OL

Guo, Suyang, OU

He, Yangyang, 06

$\mathrm{He}$, Yingwei, OV

Hong, Xueming, $\mathrm{OB}, \mathrm{Ol}$

Hou, Yan, 09

$\mathrm{Hu}$, Zhenlin, 09

Huang, Zhanhua, OF

Huo, Junjie, 10

Huo, Zhenwei, OB

Jia, Dagong, OA

Jia, Zhitai, OC

Jiang, Junfeng, 02, 04, 05, 07, OD, OH, OU

Jie, Dong, 12

Jin, Minghui, OK

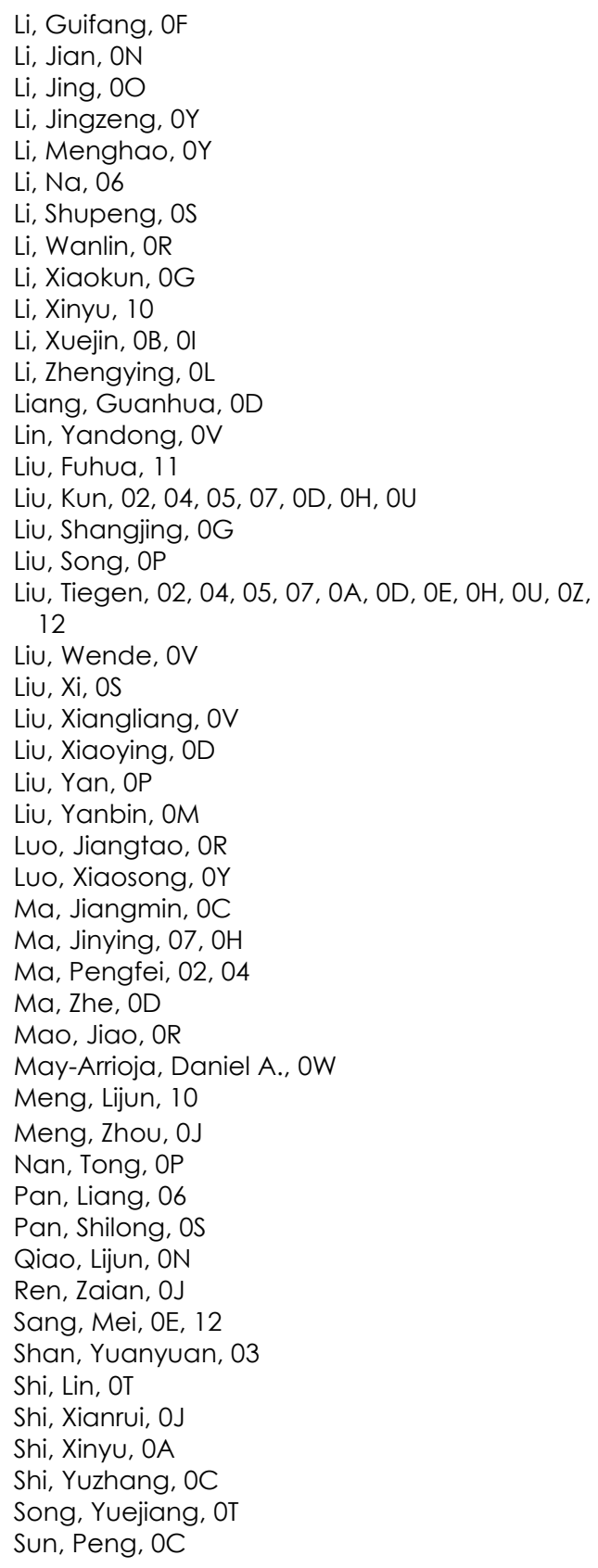


Sun, Zhenshi, 02, 04

Tang, Xiaozheng, OT

Teng, Lei, $0 Q$

Tian, Chang, 06

Tian, Guoyuan, OX

Wang, Changjia, OL

Wang, Chongxi, OF

Wang, Feng, 03, OY

Wang, Gao, OC

Wang, Haiyong, OX

Wang, Honghai, OL

Wang, Long, OX

Wang, Peng, 09

Wang, Ping, 11

Wang, Shuang, 05, OD, OE, OU, 12

Wang, Tao, ON

Wang, Xiangchuan, OS

Wang, Yao, OE, 12

Wei, Dong, 12

Wei, Xu, OT

Wen, Chaopeng, OK

Wen, Guoqiang, OA

Wen, Yuwei, 08

Wu, Jianwei, OK

Wu, Jing, OP

Wu, Wen, 05

Wu, Yongfeng, OP

Wu, Zhiyang, OU

Xiong, Bohang, OY

Xu, Gang, OL

$X \cup$, Guoliang, OR

$X u$, Nan, OV

Xu, Weihua, 09

Yang, Wei, 03

Yang, Xiaojun, 06

Yang, Yong, 06

Yao, Penghui, $0 Z$

Yao, X. Steve, $0 Z$

Yi, Duo, OB, Ol

You, Zhenxing, 08

Yu, Chunlei, OT

Yu, Xun, 05

Yuan, Xiaocong, OM

Zeng, Xiaodong, 00

Zhang, Hongxia, OA

Zhang, Jiahang, 07

Zhang, Jianzhong, ON

Zhang, Jin, 11

Zhang, Lianhao, OU

Zhang, Liwang, 02

Zhang, Mingjiang, ON

Zhang, Shan, OF

Zhang, Xiang, OT

Zhang, Xin, OT

Zhang, Xuezhi, OD

Zhang, Xuping, 03

Zhang, Yichi, OJ

Zhang, Yinxin, OF

Zhang, Yixin, 03

Zhang, Yongning, OD
Zhang, Zenan, 01

Zhang, Zhao, 07, OH

Zhao, Chong, 11

Zhao, Fan, 12

Zhao, Jian, OF

Zhao, Ningbo, OF

Zhong, Hongjun, OX

Zhou, Hanchang, OC

Zhou, Jie, OU

Zhou, Yu, OG

Zhu, Xiaofei, 06

viii

Proc. of SPIE Vol. $114361143601-8$ 


\section{Symposium Committees}

Symposium Chairs

Zheng You, CIS (China), Tsinghua University (China)

Jim M. Oschmann, Ball Aerospace (United States)

Symposium Committee

Tianchu Li, National Institute of Metrology (China)

Songlin Zhuang, University of Shanghai for Science and Technology (China)

Liwei Zhou, Beijing Institute of Technology (China)

Shenghua Ye, Tianjin University (China)

Yimo Zhang, Tianjin University (China)

Guangjun Zhang, Southeast University (China)

Technical Program Chair

Guofan Jin, Tsinghua University (China)

Technical Program Co-chairs

Jinxue Wang, SPIE

Tiegen Liu, Tianjin University (China)

Local Organizing Committee Chair

Youhua Wu, China Instrument and Control Society (China)

Local Organizing Committee Co-chairs

Guoqiang Ni, Beijing Institute of Technology (China)

Qun Hao, Beijing Institute of Technology (China)

General Secretary

Tong Zhang, China Instrument and Control Society (China)

Administrative Vice General Secretaries

Yu-nan Sun, Beijing Institute of Technology (China)

Liquan Dong, Beijing Institute of Technology (China) 
Vice General Secretaries

Yuejin Zhao, Beijing Institute of Technology (China)

Cunlin Zhang, Capital Normal University (China)

Local Organizing Committee

Hongda Chen, Institute of Semiconductors, CAS (China)

Xuping Zhang, Nanjing University (China)

Shangzhong Jin, China Jiliang University (China)

Libo Yuan, Guilin University of Electronic Technology (China)

Yongcai Guo, Chongqing University (China)

Tian Lan, Beijing Institute of Technology (China)

Cuiling Li, Beijing Institute of Technology (China) 


\title{
Conference Committee
}

\author{
Conference Chairs
}

Xuping Zhang, Nanjing University (China)

Hai Xiao, Clemson University (United States)

Conference Program Committee

Francisco J. Arregui, Universidad Pública de Navarra (Spain)

Xiaoyi Bao, University of Ottawa (Canada)

Weihong Bi, Yanshan University (China)

Kevin Chen, University of Pittsburgh (United States)

Rongshen Chen, University of Birmingham (United Kingdom)

Weimin Chen, Chongqing University (China)

Zhe Chen, Jinan University (China)

Xinyong Dong, China Jiliang University (China)

Fajie Duan, Tianjin University (China)

Xudong Fan, University of Missouri (United States)

Ming Han, University of Nebraska-Lincoln (United States)

Shibin Jiang, NP Photonics, Inc. (United States)

Wei Jin, Hong Kong Polytechnic University (Hong Kong, China)

Tiegen Liu, Tianjin University (China)

Gan-Ding Peng, University of New South Wales (Australia)

Yunjian Rao, University of Electronic Science and Technology of China (China)

Luc Thévenaz, Ecole Polytechnique Fédérale de Lausanne (Switzerland)

Tingyun Wang, Shanghai University (China)

Anbo Wang, Virginia Polytechnic Institute and State University (United States)

Feng Wang, Nanjing University (China)

Liang Wang, The Chinese University of Hong Kong (Hong Kong, China)

Tao Wei, University of Rhode Island (United United)

Libo Yuan, Guilin University of Electronic Technology (China)

Lin Zhang, Aston University (United Kingdom)

Ningmu Zou, Advanced Micro Devices (AMD) Inc. (United States)

Session Chairs

1 Distributed Optical Fiber Sensors

Liang Wang, Huazhong University of Science and Technology (China)

Changrui Liao, Shenzhen University (China)

2 Interfermeter-based Sensors

Ningmu Zou, Advanced Micro Devices (AMD) Inc. (United States)

Mingjiang Zhang, Taiyuan University of Technology (China) 
3 Distributed Optical Fiber Sensors

Hao Liang, Jinan University (China)

Junhui Hu, Guangxi Normal University (China)

$4 \quad$ Microstucture Sensors

Wei Jiang, Nanjing University (China)

Xinyong Dong, China Jiliang University (China)

5 Microstucture Sensors

Hongbao Xin, Jinan University (China)

Feng Wang, Nanjing University (China) 


\section{Introduction}

With distinct advantages such as high precision, fast response, immunity to electromagnetic interference and remote operation capability, optical sensors have traditionally been viewed as a high-end solution to many scientific and engineering problems that demand great performance. Fortunately, over the past decades, the rapid advancements in optical communications have brought to the market low cost semiconductor lasers, photo detectors, optical fibers, and integrated optical components, which pave the way for optical sensors to enter our daily lives and land on factory floors.

Optical sensors are now being used for measurement of various physical, chemical and biological parameters, providing great solutions for a wide variety of sensing needs that are difficult to handle by other types of sensors. New optical sensing devices, configurations and systems are being proposed, developed, tested and deployed at an unprecedented pace. Since 2017, scientists, researchers and engineers around the world gathered in Beijing, China to present their latest research work in the Optical Sensor and Applications Conference, as a part of the OIT Symposium.

In 2019, 37 papers have been accepted and presented (oral and poster) at the conference, covering many research fields and with a special focus on distributed and quasi-distributed optical fiber sensors. During the conference, we shared the latest accomplishments, sparked ideas, envisioned next-generation technologies, challenged ourselves, and cherished friendships.

The chairs of the OIT 2019-Optical Sensor and Applications Conference would like to thank our committee members, reviewers, authors and participants for their contributions and support that made the conference a great success. We are also grateful to the staff of SPIE for their support in publishing this volume in the Proceedings of SPIE.

\section{Xuping Zhang Hai Xiao}


Proc. of SPIE Vol. 11436 1143601-14

Downloaded From: https://www.spiedigitallibrary.org/conference-proceedings-of-spie on 26 Apr 2023 Terms of Use: https://www.spiedigitallibrary.org/terms-of-use 


\section{Conference Organizers}

Opto-Electronic-Mechanic Technology and System Integration Chapter, CIS (China)

Committee on Optoelectronic Technology, COS (China)

Committee on Optics, China Ordnance Society (China)

Optical Instrument Chapter, CIS (China)

Beijing Institute of Technology (China)

Tianjin University (China)

Tsinghua University (China)

Peking University (China)

Nanjing University (China)

Zhejiang University (China)

Nankai University (China)

Capital Normal University (China)

Beijing University of Posts and Telecommunications (China)

Chongqing University (China)

University of Shanghai for Science and Technology (China)

Instrument Society of America (United States)

Institute of Measurement and Control (United Kingdom)

Hong Kong Institution of Engineers (Hong Kong, China)

The Society of Measurement and Control (Japan) 
Proc. of SPIE Vol. 11436 1143601-16

Downloaded From: https://www.spiedigitallibrary.org/conference-proceedings-of-spie on 26 Apr 2023 Terms of Use: https://www.spiedigitallibrary.org/terms-of-use 